\section{THE 21ST CENTURY ORGANIZATION: REINVENTING THROUGH REENGINEERING}

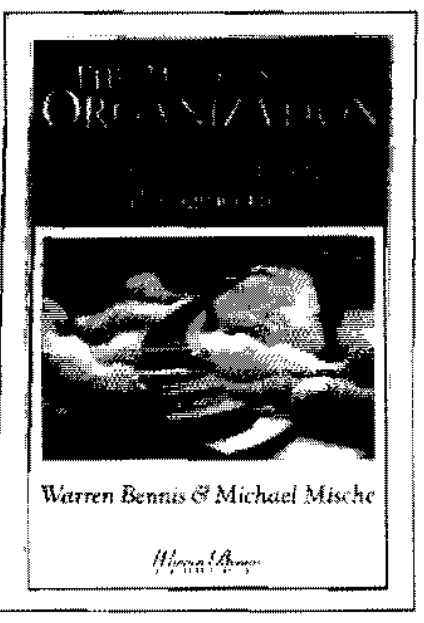

de WARREN BENNIS $\theta$ MICHAEL MISCHE USA: Pfeiffer \& Company, 1995, $116 \mathrm{p}$.

por Carlos Vinícius Maluly, Consultor, Professor da UNIP (Universidade Paulista e Faculdade Ibero-Americana) e Mestrando em Administração na EAESPIFGV.

E ntre as muitas publicaçôes recentes sobre reengenharia, The 21st century organization - reinventing through reenginering dá um tratamento envolvente ao tema, com recursos visuais didáticos e criativos.

Warren Bernis, respeitado acadêmuco norte-americano, professor emérito da Universidade de Southern, Califórnia, autor de 18 livros, incluindo o best-seller On becoming a leader, escreveu em co-autoria com Michael Mische uma série de publicaçoes que foi denominada The Warren Bennis executive briefing series. Trata-se de valioso auxilio a executivos que buscam atingir o conhecimento necessário ao bom desempenho profissional, atualização e parâmetros para comparação das suas decisões, em particular aqueles que desejam participar ativamente do processo de competição empresarial. A série reúne os títulos Fabled service: ordinary acts, extraordinary outcomes; Managing globalization in the age of interdependence $\mathrm{e}$ Coch to coach business lessons from the locker room, editados pela Pfeiffer \& Company, que se destaca pelo forte apelo da "leitura răpida": "quick read - just in two hours".

Warren Bennis tem trabalhado os conceitos relacionados com os aspectos comportamentais decorrentes do exercicio e papel das lideranças. A invenção de uma vida - reflexöes sobre lideranças e mudanţas é o seu trabalho mais recente, traduzido e publicado no Brasil pela editora Campus.
No livro em pauta, os autores ressaltam o papel dos pioneiros no estudo da reengenharia, destacando Thomas Davenport, James B. Quinn, Robert Tomasko e, especialmente, Michael Hammer e James Champy, cujo estudo sobre o tema ainda é considerado leitura básica e obrigatória.

O leitor não encontrará aí a panacéia de alguma "onda" administrativa, dessas que se prestam a reproduzir as idéias de algum "guru" ou a semear modismos no campo da administraçẫo de empresas. Ao contrário, a obra é desenvolvida com base profissional marcante. Na parceria dos autores aflora a mistura da visão acadêmica de Bennis com a experiéncia profissional de Michael Mische, que traz a sua percepção sob um enfoque empresarial, fruto da vivência $e$ atuação em importantes firmas de consultoria.

O livro apresenta, dentre outros, os exemplos da Motorola, General Electric, Hewlett-Packard, Ford Motor Company, analisados sob a ótica do sucesso empresarial. Busca-se compreender a situação e o contexto vivenciados por essas grandes empresas em processos de reengenharia, na tentativa da duplicação e aplicação de tais modelos.

Perguntas básicas ajudam o desenvolvimento do texto, que procura responder o que torna a reengenharia necessária ou quando perceber o momento certo para o inicio do processo. Desse modo, enumeram-se variáveis que irăo influenciar ou exercer impactos sobre a organização e os funcionários.

A análise de alguns fatores econômicos, da própria idéia da qualidade e dos conceitos ligados á produtividade pro picia ao leitor o entendimento da essência da formação do executivo, bem como das habilidades vitais que superam parâmetros tradicionais, revelando diferenciais competitivos e servindo, assim, como meios de instrumentalização profissional. A empresa com visão do futuro caminha preparando os seus executivos. $O$ desafio é a transformação inteligente, capaz de torná-los hábeis para competir hoje e amanhã. De certo modo, transparece ai uma visão para a "ação" estratégica.

O texto e desenvolvido com um sólido embasamento argumentativo, e o tratamento direto e a "leitura rápida" não implicam superficialidade. O primeiro capítulo discorre sobre alguns dos conceitos que são impropriamente relacionados com a reengenharia. Após a conceituação, săo apresentados os elementos considerados essenciais para sustentar a necessidade dos movimentos de mudança. Assim, o segundo capitulo trabalha com a idéia da necessidade desse processo de mudança até a sua efetivação. Uma visão histórica prepara a noção da "reinvenção" da organização por meio da reengenharia.

O terceiro capítulo aponta enfaticamente aqueles procedimentos que se deve evitar. Na seqüência, são apresentadas cinco fases que antecedem a finalização do trabalho, culminando numa análise sobre as implicaçôes quanto ao lado humano da reengenharia.

Quando os autores questionam o que é a reengenharia, tratam de apontar alguns dos mitos e realidades com ela associados com frequência. A reengenharia organizacional segundo divulgaçăo dos consultores organizacionais nos Estados Unidos, todas as empresas listadas na Fortune 500, 
estäo implementando algum processo de reengenharia. Quando se deseja assumir um posicionamento conceitual sobre as formas ou estratégias de ação para aplicaçôes da reengenharia, durante a leitura, nota-se a falta de uma esquematização das diferentes técnicas e possiveis atuaçôs. Para tal esquematizaçấo sobre as abordagens da reengenharia, e oportuno o artigo Reengenharia: um guia de referência para o executioo, de Josê Enesto Lima Gonçalves, publicado na RAE - Revista de Administração de Empresas, São Paulo, v. 34, n. 4, p. 23-30, jul./ago.1994.

Ao indagar o que é reengenharia, os autores apontam alguns dos mitos e realidades a ela associados com freqüûncia, jâ que, para eles, a atual disseminação de conceitos, ter mos ou definiçōes em torno da reengenharia levanta muitas controvérsias. Assim, contestam a noção de que a prătica da reengenharia significa pressupor que antes tudo estava sendo feito errado. Abordam-se também questós como: rengenharia e o uso da tecnologia da informação? Reengenharia significa fazer mais com menos? Ela pode ser usada para resolver um problema? Pode ser gerenciada por qualquer um? Corresponde à verdade a idéia, ou mito, de que a reengenharia é fonte geradora de medo e de ansiedade? E os autores discordam, ainda, da noçào de que a reengenharia $\mathrm{e}$ um processo científico.

Discutem, assim, o que năo é reengenharia e o que ela deveria ser. Para os autores, a reengenharia está associada com a "reinvenção" da empresa, uma prática que impulsiona a posição competitiva da empresa, dá valor aos seus acionistas e contribuiçōes à sociedade. Reconhecem, contudo, as muitas dificuldades para se conseguir implementar essa "reinvenção", e afirmam que para supera-las é necessária uma permanente orientaçẫo para a transformaçảo da organizaçăo.

Algumas atividades importantes, segundo os atores, caracterizam a reengenharia: inovaçä̌; dar ouvido aos consumidores; aprendizagem; geraçăo de idélas; desenho de novos paradigmas; antecipar-se aos concorrentes; contribuir para a melhoria da qualidade do local de trabalho; ponderar as implicaçốes sociais.

Olivro de Bennis e Mische apresenta conceitos extremamente ligados a uma postura executiva que, ao validar os processos de mudança, visa a um futuro de sucesso. A dimensão dos parâmetros por eles propostos supera a visão tradicionalista que ainda se encontra no mundo dos executivos. Ao mostrar uma nova maneira de visualizar a competição, os autores questionam alguns dos velhos paradigmas comportamentais: "Nâo sou melhor do que os outros, sou importante. Eu näo estou separado, sou parte de uma comunidade. Os outros não são meus inimigos, eles são meu benchmarking",

Se pensarmos no caso brasileiro, os autores podem nos sugerir que as empresas precisam vencer os desafios decorrentes dos problemas ligados à necessidade da reduçäo dos custos operacionais e à melhoria da qualidade e dos serviços, se quiserem obter resultados satisfatórios. É também papel relevante a adoção de medidas conciliatórias entre uso de tecnologia e desemprego, reduçầo de niveis hierárquicos e eficiência dos serviços prestados, os progra- mas de qualidade e os custos decorrentes das falhas, com resultados năo-esperados. O desafio continua sendo a prática da aprendizagem.

Na conclusăo, os autores, oportumamente, aconselham os executivos: "Dara aqueles que participam da reengenharia: a reinvençäo oferecentos como que a oportumidade de olhar num espelho, explorar o que se descobriu ecrescer. Numa andise final, a reengenharia de uma organizaçäo deve iniciar com uma reengenharia a partir de você mesmo".

\section{A ÉTICA NA POLÍTICA: VENTURAS E DESVENTURAS BRASILEIRAS}

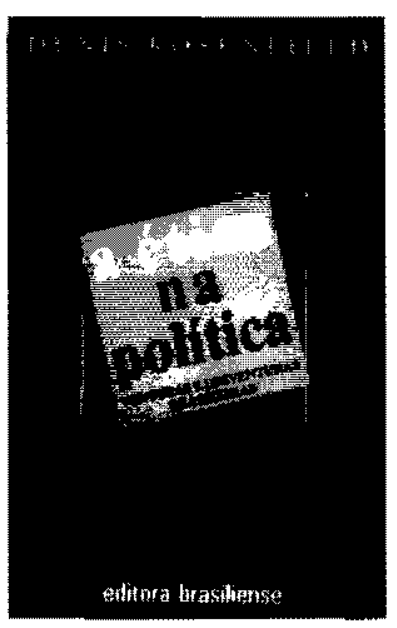

\section{de DENIS ROSENFIELD}

Săo Paulo: Brasiliense, 1992, 90 p.

por Marla Cecilia Coutinho de Arruda, Professora do Departamento de Mercadologia e Coordenadora do CENE (Centro de Estudos de Ética nos Negócios) da EAESP/FGV.

D enis Rosenfield tinha 41 anos quando escreveu este livro. Antes, vivera quatro anos no México e seis na França. Doutorou-se pela Universidade de Paris I Panthéon-Sorbonne, e atualmente é professor do Departamento de Filosofia da Universidade Federal do Rio Grande do Sul e pesquisador do CNPq. Do seu histórico constam ainda várias publicaçôes sobre filosofia política. A sua produçäo junta-se agora $A$ ética na polttica: venturas e desventuras brasileiras, uma obra que faz transparecer a preocupação humanística do autor. 